UNIVERSITE DE LAUSANNE - FACULTE DE BIOLOGIE ET DE MEDECINE

Policlinique Médicale Universitaire

Unité des Populations Vulnérables

\title{
Social and Medical Vulnerability Factors of Emergency Department Frequent Users in a Universal Health Insurance System.
}

\section{THESE}

préparée sous la direction du Docteur Patrick Bodenmann

(avec la collaboration du Prof. Jean-Bernard Daeppen)

et présentée à la Faculté de biologie et de médecine de

l'Université de Lausanne pour l'obtention du grade de

DOCTEUR EN MEDECINE

par

\section{Gilles BIELER}

WX

215

Bite

Médecin diplômé de la Confédération Suisse BMTE 3649
Originaire de Morges VD/Brig-Glis VS

Lausanne

2012 
UNIL | Université de Lausanne

Faculté de biologie et de médecine

Ecole Doctorale Doctorat en médecine

\section{Imprimatur}

Vu le rapport présenté par le jury d'examen, composé de

Directeur de thèse Monsieur le Docteur Patrick Bodenmann

Co-Directeur de thèse

Expert

Madame le Professeur Brigitte Santos-Eggimann

Directrice de l'Ecole Madame le Professeur Stephanie Clarke doctorale

la Commission MD de l'Ecole doctorale autorise l'impression de la thèse de

\section{Monsieur Gilles Bieler}

intitulée

Social and Medical Vulnerability Factors of Emergency Department Frequent Users in a Universal Health Insurance System

Lausanne, le 17 avril 2012

pour Le Doyen

de la Faculté de Biologie et de Médecine

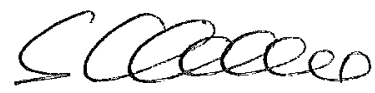

Madame le Professeur Stephanie Clark Directrice de l'Ecole doctorale 


\section{Facteurs de vulnérabilité sociaux et médicaux des patients à recours multiple aux urgences dans un système d'assurance universelle.}

\section{Objectifs}

- Identifier les facteurs de vulnérabilité sociaux et médicaux associés au recours multiple aux consultations des urgences.

- Déterminer si les patients à recours multiple sont plus à même de combiner ces facteurs dans un système d'assurance universelle.

\section{Méthode}

Il s'agit d'une étude cas-contrôle rétrospective basée sur l'étude de dossiers médico-administratifs comparant des échantillons randomisés de patients à recours multiple à des patients n'appartenant pas à cette catégorie, au sein des urgences du Centre Hospitalier Universitaire Vaudois et de la Policlinique Médicale Universitaire de Lausanne. Les auteurs ont défini les patients à recours multiple comme comptabilisant au moins quatre consultations aux urgences durant les douze mois précédents. Les patients adultes ( $>18$ ans) ayant consulté les urgences entre avril 2008 et mars 2009 (période d'étude) étaient inclus; ceux quittant les urgences sans décharge médicale étaient exclus. Pour chaque patient, le premier dossier d'urgence informatisé inclus dans la période d'étude était sélectionné pour l'extraction des données.

Outre les variables démographiques de base, les variables d'intérêt comprennent des caractéristiques sociales (emploi, type de résidence) et médicales (diagnostic principal aux urgences). Les facteurs sociaux et médicaux significatifs ont été utilisés dans la construction d'un modèle de régression logistique, afin de déterminer les facteurs associés avec le recours multiple aux urgences. De plus, la combinaison des facteurs sociaux et médicaux a été étudiée.

\section{Résultats}

Au total, 359/1'591 patients à recours multiple et 360/34'263 contrôles ont été sélectionnés. Les patients à recours multiple représentaient moins d'un vingtième de tous les patients des urgences (4.4\%), mais engendraient $12.1 \%$ de toutes les consultations $\left(5^{\prime} 813 / 48^{\prime} 117\right)$, avec un record de 73 consultations. Aucune différence en termes d'âge ou de genre n'est apparue, mais davantage de patients à recours multiples étaient d'une nationalité autre que suisse ou européenne ( $n=117$ [32.6\%] vs $n=83$ [23.1\%], $p=0.003$ ). L'analyse multivariée a montré que les facteurs de vulnérabilité sociaux et médicaux les plus fortement associés au recours multiple aux urgences étaient : être sous tutelle (Odds ratio [OR] ajusté $=15.8$; intervalle de confiance [IC] à $95 \%=1.7$ à 147.3), habiter plus proche des urgences (OR ajusté $=4.6$; IC95\% $=2.8$ à 7.6), être non assuré (OR ajusté $=2.5 ;$ IC95\% $=$ 1.1 à 5.8), être sans emploi ou dépendant de l'aide sociale (OR ajusté $=2.1 ;$ IC95\% $=1.3$ à 3.4), le nombre d'hospitalisations psychiatriques (OR ajusté $=4.6$; IC95\% $=1.5$ à 14.1), ainsi que le recours à au moins cinq départements cliniques différents durant une période de douze mois (OR ajusté = 4.5; IC95\% = 2.5 à 8.1). Le fait de comptabiliser deux sur quatre facteurs sociaux augmente la vraisemblance du recours multiple aux urgences (OR ajusté $=5.4 ;$ IC95\% $=2.9$ à 9.9); des résultats similaires ont été trouvés pour les facteurs médicaux (OR ajusté $=7.9 ;$ IC95\% $=4.6$ à 13.4). La combinaison de facteurs sociaux et médicaux est fortement associée au recours multiple aux urgences, puisque les patients à recours multiple étaient dix fois plus à même d'en comptabiliser trois d'entre eux (sur un total de huit facteurs, IC95\% $=5.1$ à 19.6).

\section{Conclusion}

Les patients à recours multiple aux urgences représentent une proportion modérée des consultations aux urgences du Centre Hospitalier Universitaire Vaudois et de la Policlinique Médicale Universitaire de Lausanne.

Les facteurs de vulnérabilité sociaux et médicaux sont associés au recours multiple aux urgences. En outre, les patients à recours multiple sont plus à même de combiner les vulnérabilités sociale et médicale que les autres.

Des stratégies basées sur le case management pourraient améliorer la prise en charge des patients à recours multiple avec leurs vulnérabilités afin de prévenir les inégalités dans le système de soins ainsi que les coûts relatifs. 


\section{Social and Medical Vulnerability Factors of Emergency Department Frequent Users in a Universal Health Insurance System}

Gilles Bieler, Sophie Paroz, MA, Mohamed Faouzi, PhD, Lionel Trueb, MD, Paul Vaucher, MSc, Fabrice Althaus, MD, Jean-Bernard Daeppen, MD, and Patrick Bodenmann, MD, MSc

\section{Abstract}

Objectives: The objectives were to identify the social and medical factors associated with emergency department $(E D)$ frequent use and to determine if frequent users were more likely to have a combination of these factors in a universal health insurance system.

Methods: This was a retrospective chart review case control study comparing randomized samples of frequent users and nonfrequent users at the Lausanne University Hospital, Switzerland. The authors defined frequent users as patients with four or more ED visits within the previous 12 months. Adult patients who visited the ED between April 2008 and March 2009 (study period) were included, and patients leaving the ED without medical discharge were excluded. For each patient, the first ED electronic record within the study period was considered for data extraction. Along with basic demographics, variables of interest included social (employment or housing status) and medical (ED primary diagnosis) characteristics. Significant social and medical factors were used to construct a logistic regression model, to determine factors associated with frequent ED use. In addition, comparison of the combination of social and medical factors was examined.

Results: A total of 359 of 1,591 frequent and 360 of 34,263 nonfrequent users were selected. Frequent users accounted for less than a 20 th of all ED patients $(4.4 \%)$, but for $12.1 \%$ of all visits $(5,813$ of 48,117$)$, with a maximum of 73 ED visits. No difference in terms of age or sex occurred, but more frequent users had a nationality other than Swiss or European ( $n=117[32.6 \%]$ vs. $n=83[23.1 \%], p=0.003)$. Adjusted multivariate analysis showed that social and specific medical vulnerability factors most increased the risk of frequent ED use: being under guardianship (adjusted odds ratio $[\mathrm{OR}]=15.8 ; 95 \%$ confidence interval $[\mathrm{CI}]=1.7$ to 147.3), living closer to the $\mathrm{ED}$ (adjusted $\mathrm{OR}=4.6 ; 95 \% \mathrm{CI}=2.8$ to 7.6 ), being uninsured (adjusted $\mathrm{OR}=2.5$; $95 \% \mathrm{CI}=1.1$ to 5.8 ), being unemployed or dependent on government welfare (adjusted $\mathrm{OR}=2.1 ; 95 \%$ $\mathrm{CI}=1.3$ to 3.4 ), the number of psychiatric hospitalizations (adjusted $\mathrm{OR}=4.6 ; 95 \% \mathrm{CI}=1.5$ to 14.1 ), and the use of five or more clinical departments over 12 months (adjusted $\mathrm{OR}=4.5 ; 95 \% \mathrm{CI}=2.5$ to 8.1 ). Having two of four social factors increased the odds of frequent ED use (adjusted $=$ OR $5.4 ; 95 \% \mathrm{CI}=2.9$ to 9.9 ), and similar results were found for medical factors (adjusted $\mathrm{OR}=7.9 ; 95 \% \mathrm{CI}=4.6$ to 13.4 ). A combination of social and medical factors was markedly associated with ED frequent use, as frequent users were 10 times more likely to have three of them (on a total of eight factors; $95 \% \mathrm{CI}=5.1$ to 19.6).

Conclusions: Frequent users accounted for a moderate proportion of visits at the Lausanne ED. Social and medical vulnerability factors were associated with frequent ED use. In addition, frequent users were more likely to have both social and medical vulnerabilities than were other patients. Case management strategies might address the vulnerability factors of frequent users to prevent inequities in health care and related costs

ACADEMIC EMERGENCY MEDICINE 2012; 19:63-68 @ 2012 by the Society for Academic Emergency Medicine

From the Department of Ambulatory Care and Community Medicine (GB, PV, FA, PB), Institute of Social and Preventive Health (MF), University of Lausanne, Lausanne, Switzerland; the Department of Community Medicine and Health (SP), Emergency Department (LT), Alcohol Treatment Center, Department of Community Medicine and Health (JBD), Lausanne University Hospital, Lausanne, Switzerland.

Received July 24, 2011; revision received August 4, 2011; accepted September 5, 2011

Presented at the Society of General Internal Medicine, Minneapolis, MN, April 2010; the Swiss Society of Internal Medicine, Basel, Switzerland, May 2010; and the Swiss Public Health Conference, Nottwil, Switzerland, September 2010.

This study was entirely supported by our institution.

The authors have no conflicts of interest to disclose.

Supervising Editor: Lowell Gerson, PhD.

Address for correspondence and reprints: Dr. P. Bodenmann; e-mail: patrick.bodenmann@hospvd.ch. 
A Ithough most patients visit emergency departments (EDs) infrequently and for isolated problems, some patients are frequent users of emergency care. ${ }^{1}$ Definitions of ED frequent use vary from three to 12 ED visits over a 12 -month period. ${ }^{2}$ Frequent users comprise $0.3 \%$ to $8 \%$ of all ED patients and account for $3.5 \%$ to $28 \%$ of ED visits in developed countries. $^{3-5}$ This population has complex needs ${ }^{6,7}$ and both social and medical problems. ${ }^{8}$ Understanding the features of these patients is vital if their medical care is to be improved. In addition, since the needs and socioeconomic status of ED patients may vary greatly between national sectors and countries, it becomes important to characterize frequent users at the local level.

Research on frequent user patients shows that they are more "vulnerable" than other ED patients due to poverty, homelessness, or chronic illness. ${ }^{4,-11}$ Social science and nursing researchers have generally defined a vulnerable population as those who are at increased risk for poor physical, psychological, or social health outcomes and inequities in health care. ${ }^{12-16}$ In our design, vulnerability was defined as an accumulation of specific social and medical factors. We hypothesized that patients having multiple vulnerable factors would be more likely to use the ED frequently, even when financial considerations are removed in a country with universal health insurance. Our goal was to identify the social and medical vulnerability factors associated with frequent ED use and determine if frequent users were more likely to experience both social and medical problems.

\section{METHODS}

\section{Study Design}

This was a retrospective study comparing randomly selected samples of frequent users to nonfrequent users in the ED of the Lausanne University Hospital from April 2008 to March 2009. Since no standard definition of frequent users exists, we chose the commonly used definition of four or more ED visits within the previous 12 months, $^{2}$ to allow comparison with other studies. The institutional ethics committee approved the research.

\section{Study Setting and Population}

The study took place at the Lausanne University Hospital (one of five university hospitals in Switzerland), which provides more than 45,000 annual ED visits and services 770,000 people. The hospital's psychiatric department has a separate ED for mentally ill patients. The Lausanne population consists of $42.7 \%$ foreigners (other than Swiss citizenship) and has an unemployment rate of $4.3 \%$ at the time of the study. The Swiss health system is based on public hospitals, private clinics, and outpatient care. Health insurance is mandatory and managed by private companies, offering identical basic health coverage to the whole population for public hospitals and outpatient care together, with optional coverage for private clinics.

\section{Study Protocol}

Patients who were age 18 years or older were included if they made at least one ED visit between April 2008 and March 2009 (study period); those leaving the ED without a medical discharge were not included. For each included patient, we examined all ED visits over the prior 12 months for each visit within the study period. Frequent users were defined as having at least one series of four or more ED visits over the prior 12 months. Nonfrequent users (controls) were patients with up to three ED visits over the prior 12 months. All patients were sorted in the two defined groups. Computerized randomization was performed in each group selecting 359 frequent users and 360 nonfrequent users. The electronic medical record for the first ED appearance of each patient during the study period was used to extract demographic and outcome data.

\section{Measurements}

Patient identification codes were used to access local electronic databases and to extract basic demographics (age, sex, and nationality), as well as variables from which social and medical vulnerability factors could be constructed. Social vulnerability was determined by these variables: marital status (separated, divorced, or widowed), employment (unemployed or receiving government welfare grants corresponding to at least half of the personal income and allocated for long-term physical or psychiatric diseases), household (homeless or institutionalized), insurance (uninsured included patients with no insurance and asylum seekers whose insurance is government paid with minimum coverage), legal assistance (under guardianship), and travel distance from each patient's home to the ED conly patients living within the area served by the university hospital were considered). We grouped unemployment with dependence on government welfare, since these two items were recorded in the ED database as mutually exclusive outcomes. Although this combination variable cannot be directly compared with other studies, both of these factors are known to be associated with ED frequent use. ${ }^{17,18}$ Medical vulnerability was determined by ED primary diagnosis (substance abuse and mental disorder), ED arrival at night (23:00 to 08:00 hours), higher numbers of hospitalizations (lasting over 24 hours), length of stay for each hospitalization, using five or more different clinical departments (from a total of 39 departments-research-related departments were excluded) over the 12-month study period, and having no primary care physician (PCP).

To explore how vulnerability factors combined in frequent users and nonfrequent users, we selected four social (guardianship, marital status, employment, and insurance) and four medical (ED primary diagnosis of substance abuse, $\geq 6$ medical or $\geq 1$ psychiatric days hospitalized, and the use of at least five clinical departments used within the study period). Combinations of social, medical, and of both social and medical vulnerability factors were then analyzed. Manual data extraction supervised by the lead author (GB) from the electronic databases was required for the following variables: ED primary diagnosis, distance from the patient's home to the ED, having a $\mathrm{PCP}$, and number of somatic and psychiatric hospitalizations. The patient's main diagnosis was extracted using physicians' final electronic reports. If the physician reported more than 
one diagnosis, the one most related to the patient's reported chief complaint at admission was used. The chief complaint was electronically recorded and available for all patients. All remaining variables and demographic data were automatically extracted by our local data warehouse.

\section{Data Analysis}

Data from all selected patients $(n=719)$ were analyzed using STATA version 10.0 (StataCorp, College Station, TX). Statistical power was 0.90 at an overall significance level $\alpha=0.05$. Sample size was then calculated for detecting clinical significant differences for each studied factor. We used Bonferroni correction to maintain an overall $\mathrm{p}$-value of 0.05 for all 17 variables and therefore used an adjusted significant level of $\alpha^{\prime}=0,0029$. The largest requested sample $(n=719)$ was calculated for detecting a $10 \%$ absolute difference of patients without insurance coverage between groups $(95 \%$ vs. $85 \%)$. Intra- (GB) and interrater (with $\mathrm{GB}$ and $\mathrm{PB}$ independently extracting data) reliability using raw agreement coefficient were calculated on 30 random frequent users, to assess variability in the manual extraction process for the ED primary diagnosis.

Means and standard deviations $( \pm S D)$ for continuous variables and numbers and percentages for categorical variables are presented. Comparison of the frequent user and nonfrequent user groups was accomplished using Wilcoxon rank-sum and two-sample tests of proportion. Because this study focused on vulnerability, outcome data falling outside of this scope will not be presented.

Analysis of complete cases only was adopted for the multivariable analysis. Factors significantly associated with ED frequent use identified by univariate analysis were fitted in the multivariable model. Hosmer-Lemeshow goodness-of-fit statistic was calculated.

\section{RESULTS}

Frequent users accounted for $12.1 \%(5,813$ of 48,817$)$ of total ED visits, although they represent $4.4 \%(1,591$ of $35,854)$ of all patients attending the ED within the study period. The record for most visits was obtained by a patient with $73 \mathrm{ED}$ visits over 12 months. In our sample of nonfrequent users, 258 accounted for one, 71 for two, and 31 for three ED visits. Among frequent users, 171 accounted for four, 75 for five, 39 for six, 31 for seven, 11 for eight, 9 for nine, and 23 for 10 or more ED visits. Raw agreement between raters for 30 random charts was of $96.7 \%$, and for the same rater it was $100 \%$.

The descriptive results shown in Table 1 indicate that frequent users were no different in terms of age and sex, but were more often of nationality other than Swiss or European. They were socially more vulnerable, as they were more often divorced or separated, unemployed or dependent on government welfare, uninsured, institutionalized or under guardianship, and living closer to the ED. They also showed significantly more medical vulnerabilities, such as more substance abuse and mental disorders, more hospitalizations for somatic and psychiatric problems (along with more inpatient days in treatment for these disorders), and they made more use of five or more clinical

\begin{tabular}{|c|c|c|c|}
\hline $\begin{array}{l}\text { Vulnerability } \\
\text { Factors }\end{array}$ & $\begin{array}{c}\text { Frequent } \\
\text { users, } \\
\text { Mean (SD) } \\
\text { or } n(\%)\end{array}$ & $\begin{array}{c}\text { Other } \\
\text { patients, } \\
\text { Mean (SD) } \\
\text { or } n(\%)\end{array}$ & p-value* \\
\hline \multicolumn{4}{|l|}{ Demographics } \\
\hline Age, $\operatorname{Vr}(n=697)$ & $44.7( \pm 20.9)$ & $45.7\{ \pm 21.0\}$ & NSt \\
\hline Sex (female) & $172(47.9)$ & $173(48.1)$ & NS $\ddagger$ \\
\hline \multicolumn{4}{|l|}{ Nationality } \\
\hline Switzerland & $182(50.7)$ & $194\langle 53.9)$ & NSt \\
\hline $\begin{array}{l}\text { European Union } \\
(n=27)\end{array}$ & $60(16.7)$ & $83(23.1)$ & $0.04 \ddagger$ \\
\hline Other & $117(32.6)$ & $83(23.1)$ & $0.003 f$ \\
\hline \multicolumn{4}{|l|}{ Social } \\
\hline \multicolumn{4}{|l|}{ Marital status } \\
\hline $\begin{array}{l}\text { Separated or } \\
\text { divorced }\end{array}$ & $71(19.8)$ & $40(11.1)$ & $0.001 t$ \\
\hline Widowed & $31(8.6)$ & $35(9.8)$ & NSt \\
\hline \multicolumn{4}{|c|}{ Employment $\langle n=709\rangle$} \\
\hline $\begin{array}{l}\text { Unemployed or } \\
\text { dependent on } \\
\text { government } \\
\text { welfare }\end{array}$ & $116(32.3)$ & $50(14.1)$ & $<0.001 f$ \\
\hline \multicolumn{4}{|l|}{ Household } \\
\hline Homeless & $2(0.6)$ & $2(0.6)$ & NSt \\
\hline Institutionalized & $23(6.4)$ & $12(3.3)$ & NSt \\
\hline \multicolumn{4}{|l|}{ Health insurance } \\
\hline Uninsured§ & $38(10.6)$ & $14(3.9)$ & 0.0017 \\
\hline \multicolumn{4}{|l|}{ Legal assistance } \\
\hline $\begin{array}{l}\text { Under } \\
\text { guardianship }\end{array}$ & $18(5.0)$ & $3(0.8)$ & $0.001 \pm$ \\
\hline $\begin{array}{l}\text { Distance from home } \\
\text { to } \mathrm{ED}<10 \mathrm{~km} \\
(\mathrm{n}=696)\end{array}$ & $301(87.3)$ & $242(69.0)$ & $<0.001 \ddagger$ \\
\hline \multicolumn{4}{|l|}{ Medical } \\
\hline \multicolumn{4}{|c|}{ ED primary diagnosis $(n=695)$} \\
\hline Injury & $41(12,0)$ & $88(24.9)$ & $<0.001+$ \\
\hline Substance abuse & $42(12.3)$ & $23(6.5)$ & 0.02 \\
\hline Mental disorder & $32(9.4)$ & $7(2.0)$ & $<0.001 \ddagger$ \\
\hline Other & $227(66.4)$ & $235(66.6)$ & NSt \\
\hline $\begin{array}{l}\text { ED arrival at night } \\
(23: 00-08: 00\end{array}$ & $61(17.0)$ & $56(15.6)$ & NS \\
\hline \multicolumn{4}{|l|}{ hours) } \\
\hline \multicolumn{4}{|c|}{ Number of hospitalizationsll } \\
\hline Somatic & $1.09( \pm 1.66)$ & $0.41( \pm 0.86)$ & $<0.001 \dagger$ \\
\hline Psychiatric & $0.31( \pm 1.37)$ & $0.03( \pm 0.25)$ & $<0.001 \uparrow$ \\
\hline \multicolumn{4}{|c|}{ Number of days hospitalizedll } \\
\hline Somatic & $16.7( \pm 33.0)$ & $5.3( \pm 16.2)$ & $<0.001 \uparrow$ \\
\hline Psychiatric & $7.6( \pm 30.1)$ & $1.6( \pm 16.3)$ & $<0.001 \uparrow$ \\
\hline $\begin{array}{l}\text { Use of } \geq 5 \text { clinical } \\
\text { departmentsll }\end{array}$ & $127(36.9)$ & $28(7.9)$ & $<0.001 \ddagger$ \\
\hline $\begin{array}{l}\text { Having no PCP } \\
(n=644)\end{array}$ & $72(21.4)$ & $58(18.8)$ & $N S \ddagger$ \\
\hline \multicolumn{4}{|c|}{$\begin{array}{l}\text { NS = nonsignificant; } P C P=\text { primary care physician. } \\
\text { * p-values are given without adjustment for multiple testing. Overall } \\
\text { p-values can be calculated using Bonferroni correction and multiply- } \\
\text { ing p-values by } 17 \text {. } \\
\text { WWilcoxon rank-sum test. } \\
\text { †Two-sample test of proportions. } \\
\text { \$Also includes asylum seekers. } \\
\text { IIMeasured within the study period (April } 2008 \text { to March 2009). }\end{array}$} \\
\hline
\end{tabular}

departments. We expected that frequent users would be more likely to show up at night in the ED and have no PCP, but this was not the case within our sample.

Variables significantly associated with frequent users (Table 1) were used to calculate unadjusted odds ratios (ORs) of vulnerability factors individually associated with ED frequent use (Table 2). Socially, being assigned 
to guardianship, being unemployed or dependent on government welfare, and being uninsured greatly increased the risk of frequent use, as did living closer to

\section{Table 2}

Vulnerability Factors Associated With ED Frequent Use: Results From Multivariate Analysis

\begin{tabular}{|c|c|c|}
\hline Outcomes $\left(n=665^{*}\right)$ & $\begin{array}{l}\text { Unadjusted } \\
\text { OR }\end{array}$ & $\begin{array}{l}\text { Adjusted OR } \\
(95 \% \mathrm{Cl})\end{array}$ \\
\hline \multicolumn{3}{|l|}{ Social } \\
\hline $\begin{array}{l}\text { Under guardianship } \\
\text { (ref = others) }\end{array}$ & 6.3 & $15.8(1.7-147.3)$ \\
\hline $\begin{array}{l}\text { Distance from home } \\
\text { to } E D<10 \mathrm{~km} \\
\text { (ref } \geq 10 \mathrm{~km} \text { ) }\end{array}$ & 3.1 & $4.6(2.8-7.6)$ \\
\hline $\begin{array}{l}\text { Uninsured } \\
\text { (ref = insured) }\end{array}$ & 2.9 & $2.5(1.1-5.8)$ \\
\hline $\begin{array}{l}\text { Unemployed or } \\
\text { dependent on } \\
\text { government welfare } \\
\text { (ref = active } \$ \text { ) }\end{array}$ & 3.0 & $2.1(1.3-3.4)$ \\
\hline \multicolumn{3}{|l|}{ Medical } \\
\hline $\begin{array}{l}\text { Psychiatric } \\
\text { hospitalizations } \dagger \\
\text { (ref }=\text { no } \\
\text { hospitalization) }\end{array}$ & 3.5 & $4.6(1.5-14.1)$ \\
\hline $\begin{array}{l}\text { Use of } \geq 5 \text { clinical } \\
\text { departments } \uparrow(\text { ref }<5)\end{array}$ & 6.8 & $4.5(2.5-8.1)$ \\
\hline \multicolumn{3}{|c|}{ ED primary diagnosis (ref $=$ injury) } \\
\hline Substance abuse & 3.9 & $1.5(0.7-3.5) \mathrm{NS}$ \\
\hline Mental disorders & 2.3 & $1.7(1.1-2.8)$ \\
\hline $\begin{array}{l}\text { Somatic } \\
\text { hospitalizations } \dagger \\
\text { (ref }=\text { no } \\
\text { hospitalization) }\end{array}$ & 1.6 & $1.5(1.3-1.8)$ \\
\hline \multicolumn{3}{|c|}{$\begin{array}{l}\text { *Only fully completed data were used in the multivariate } \\
\text { analysis. } \\
\text { §Includes (un)paid work, students, and mentioned house- } \\
\text { wives. } \\
\text { †Measured within the study period (April } 2008 \text { to March } \\
2009 \text { ). } \\
\text { NS = nonsignificant. }\end{array}$} \\
\hline
\end{tabular}

the ED and being separated or divorced. Medically, these factors were represented by using five or more clinical departments during the study period, accounting for more somatic and psychiatric hospitalizations, and having an ED primary diagnosis of substance abuse or a mental disorder. Significant variables identified at the univariate level were used to construct the multivariate model, after excluding any redundant variables.

Adjusting for other exposures, patients who were under guardianship were 15.8 times more likely (95\% confidence interval $[\mathrm{CI}]=1.7$ to 147.3 ), those living less than $10 \mathrm{~km}$ from the ED were 4.6 times more likely $(95 \% \mathrm{CI}=2.8$ to 7.6$)$, those uninsured were 2.5 times more likely $(95 \% \mathrm{CI}=1.1$ to 5.8$)$, and those unemployed or dependent on government welfare were 2.1 times more likely $(95 \% \mathrm{CI}=1.3$ to 3.4$)$ to be frequent $\mathrm{ED}$ users. For medical factors, patients accounting for more psychiatric hospitalizations were 4.6 times more likely $(95 \% \mathrm{CI}=1.5$ to 14.1$)$, those using five or more clinical departments over 12 months were 4.5 times more likely $(95 \% \mathrm{CI}=2.5$ to 8.1$)$, those having an $\mathrm{ED}$ primary diagnosis of mental disorder 1.7 times more likely $(95 \% \quad C I=1.1$ to 2.8$)$, and those accounting for more somatic hospitalizations were 1.5 times more likely $(95 \% \mathrm{CI}=1.3$ to 1.8$)$ to be frequent users. Hosmer-Lemeshow goodness-of-fit test using 15 quantiles revealed little difference between observed and predicted values $\left(\chi^{2}=8.19, p=0.61\right)$.

Combinations of social factors were associated with ED frequent use at every level (Table 3), as illustrated for patients accumulating two on a total of four factors (adjusted $\mathrm{OR}=5.4,95 \% \mathrm{CI}=2.9$ to 9.9 ). Analog results were obtained for medical factors (adjusted $\mathrm{OR}=7.9$, $95 \% \mathrm{CI}=4.6$ to 13.4 for two factors). The combination of both social and medical factors was markedly associated with ED frequent use. Frequent users were 10 times more likely to accumulate three of them (on a total of eight; $95 \% \mathrm{CI}=5.1$ to 19.6 ).

Table 3

Cumulated Social and Medical Vulnerability Factors in Frequent Users and Other Patients

\begin{tabular}{|c|c|c|c|c|}
\hline Factors $(n)$ & Frequent users, $n(\%)$ & Other patients, $n(\%)$ & Unadjusted OR $(95 \% \mathrm{Cl})$ & Adjusted ${ }^{*}$ OR $(95 \% \mathrm{Cl})$ \\
\hline \multicolumn{5}{|l|}{ Social } \\
\hline 0 & $189(53.2)$ & $263(74.5)$ & - & - \\
\hline 1 & $100(28.2)$ & $76(21.5)$ & $1.8(1.3-2.6)$ & $1.9(1.3-2.7)$ \\
\hline 2 & $57(16.1)$ & $14(4.0)$ & $5.7(3.1-10.5)$ & $5.4(2.9-9.9)$ \\
\hline 3 & $9(2,5)$ & $0(0.0)$ & $-\uparrow$ & $-\dagger$ \\
\hline 4 & $0(0.0)$ & $0(0.0)$ & - & - \\
\hline \multicolumn{5}{|l|}{ Medical } \\
\hline 0 & $128(37.4)$ & $245(69.4)$ & - & - \\
\hline 1 & $93(27.2)$ & $77(21.8)$ & $2.3(1.6-3.3)$ & $3.2(2.1-4.8)$ \\
\hline 2 & $82(24.0)$ & $29(8.2)$ & $5.4(3.4-8.7)$ & $7.9(4.6-13.4)$ \\
\hline 3 & $28(8.2)$ & $1(0.3)$ & $53.6(7.2-398.4)$ & $75.4(10.0-570.2)$ \\
\hline 4 & $11(3.2)$ & $1(0.3)$ & $21.1(2.7-164.9)$ & $20.9(2.6-165.7)$ \\
\hline \multicolumn{5}{|c|}{ Combination } \\
\hline 0 & $79(188)$ & $188(54.3)$ & - & - \\
\hline 1 & $75(22.2)$ & $99(28.6)$ & $1.8(1.2-2.7)$ & $2.2(1.4-3.3)$ \\
\hline 2 & $88(26.0)$ & $42(12.1)$ & $5.0(3.2-7.8)$ & $6.2(3.7-10.1)$ \\
\hline 3 & $51(15.1)$ & $14(4.1)$ & $8.7(4.5-16.6)$ & $10.0(5.1-19.6)$ \\
\hline$\geq 4$ & $45(13.3)$ & $3(0.9)$ & $35.7(10.8-118.3)$ & $37.7(11.3-125.5)$ \\
\hline $\begin{array}{l}\text { *Adjuste } \\
\text { †Not calc } \\
+ \text { Social a }\end{array}$ & $\begin{array}{l}\text { ge and sex. } \\
\text { mber of subjects to }\end{array}$ & & & \\
\hline
\end{tabular}




\section{DISCUSSION}

This study sought to identify the social and medical vulnerability factors associated with frequent ED use in Switzerland and to determine if frequent users were more likely to have a combination of these factors. Less than $5 \%$ of ED patients had four or more visits, but these patients accounted for more than $12 \%$ of all ED visits. This finding agrees with previous studies. ${ }^{3,4}$ In our study, the most significant social factors associated with increased ED use were linked with guardianship, living closer to the $\mathrm{ED},{ }^{19}$ having no insurance, and being unemployed or dependent on government welfare. There were very few homeless patients $(n=4)$ in our samples. Homelessness varies greatly between cities and countries and is a major factor in frequent ED use for some institutions. ${ }^{20}$

Our most important medical factors included the use of more than five medical services over 12 months and higher numbers of medical and psychiatric hospitalizations. Substance abuse was the primary ED diagnosis for $12.3 \%$ of frequent users and $6.5 \%$ of other patients, which is slightly higher than the respective 4.3 and $1 \%$ that Fuda and Immekus ${ }^{21}$ found. Those same authors did find fewer cases of injury among frequent users (17\% vs. $32 \%$ ) than among nonfrequent users, as did we (12\% vs. $25 \%)$. A primary diagnosis of mental disorder was found in $9.4 \%$ versus $2.0 \%$ of patients, respectively, which is consistent with previous findings. $4,18,21$ As mentioned, the psychiatric department at our institution has its own ED for mentally ill patients, which may weaken the strength of the association. Additionally, we examined only primary ED diagnoses, precluding any analyses bearing on psychiatric comorbidity. We used several different variables to assess the use of medical services (number of medical and psychiatric hospitalizations and days hospitalized and the use of five or more clinical departments). All of them were associated with frequent ED use. This suggests that frequent users are more ill and need a more specialized level of health care than do other ED patients. Of note, frequent users showed a nonsignificant trend toward being more likely to have a PCP. ${ }^{22}$

In addition, our results strongly indicate that ED frequent users are more likely to accumulate social and medical vulnerability factors. This approach has not been much studied before and might be helpful in better characterization of this vulnerable population.

\section{LIMITATIONS}

Several potential methodologic limitations should be considered when interpreting these results. Using medical charts to extract outcome data constrains the scope of measurable vulnerability factors. Although this technique has been used in many other frequent user studies in the ED setting, ${ }^{17,23}$ we cannot exclude that other determinants that were not collected could also be good indicators of ED frequent use. Another major limitation is conducting the research at a single location. This is one of the most frequent methodologic problems found in ED research on frequent users, ${ }^{3,23,24}$ In addition, since ED use is subject to local specificities dictated by the health system structure, generalization of our results to other EDs and its users is not possible. Health insurance in Switzerland is mandatory, but some of the particularly vulnerable individuals still lack coverage, and although ED access is unrestricted, emergency care is not free. The accuracy of data contained in medical charts is also a concern. For example, whether or not a patient actually has a PCP depends largely on what the patient reports to the resident treating him or her, as well as what is ultimately written into the medical charts. The PCPs were not contacted to check or verify the recorded status.

\section{CONCLUSIONS}

Frequent users accounted for a moderate proportion of ED visits at our institution. Social and medical vulnerability factors were positively associated with frequent use of the ED. Frequent users were more likely to have a combination of social and medical vulnerability factors than were the nonfrequent users. Realizing this has important implications for government-funded hospitals. Future case management strategies may help address the specific needs and vulnerabilities of frequent users and prevent inequalities of care within this population and could reduce health care system costs.

We thank the Department of Ambulatory Care and Community Medicine, University of Lausanne, for entirely funding the study, and Mr. N. Larqué from our local data warehouse, Mrs. S. Stucki, and Dr I. Labgaa for their precious help.

\section{References}

1. Hoot NR, Aronsky D. Systematic review of emergency department crowding: causes, effects, and solutions. Ann Emerg Med. 2008; 52:126-36.

2. Moore L, Deehan A, Seed P, Jones R. Characteristics of frequent attenders in an emergency department: analysis of 1-year attendance data. Emerg Med J. 2009; 26:263-7.

3. Ovens HJ, Chan BT. Heavy users of emergency services: a population-based review. CMAJ. 2001; 165:1049-50.

4. Hunt KA, Weber EJ, Showstack JA, Colby DC, Callaham ML. Characteristics of frequent users of emergency departments. Ann Emerg Med. 2006; $48: 1-8$.

5. Lacalle E, Rabin E. Frequent users of emergency departments: the myths, the data, and the policy implications. Ann Emerg Med. 2010; 56:42-8.

6. Olsson M, Hansagi $H$. Repeated use of the emergency department: qualitative study of the patient's perspective. Emerg Med J. 2001; 18:430-4.

7. Sun BC, Burstin HR, Brennan TA. Predictors and outcomes of frequent emergency department users. Acad Emerg Med. 2003; 10:320-8.

8. Malone RE. Almost 'like family': emergency nurses and 'frequent flyers'. J Emerg Nurs. 1996; 22:17683.

9. Kennedy D, Ardagh M. Frequent attenders at Christchurch Hospital's emergency department: a 4-year study of attendance patterns. $N$ Z Med J. 2004; 117:U871. 
10. Okin RL, Boccellari A, Azocar F, et al. The effects of clinical case management on hospital service use among ED frequent users. Am J Emerg Med. 2000; 18:603-8.

11. Byrne M, Murphy AW, Plunkett PK, McGee HM, Murray A, Bury G. Frequent attenders to an emergency department: a study of primary health care use, medical profile, and psychosocial characteristics. Ann Emerg Med. 2003; 41:309-18.

12. Flaskerud $\mathrm{JH}$, Winslow BJ. Conceptualizing vulnerable populations health-related research. Nurs Res. 1998; 47:69-78.

13. Aday LA. Health status of vulnerable populations. Annu Rev Public Health. 1994; 15:487-509.

14. Fiscella K, Franks P, Gold MR, Clancy CM. Inequality in quality: addressing socioeconomic, racial, and ethnic disparities in health care. JAMA. 2000; 283:2579-84.

15. Shi L, Stevens GD. Vulnerability and unmet health care needs. The influence of multiple risk factors. J Gen Intern Med. 2005; 20:148-54.

16. Mechanic D, Tanner J. Vulnerable people, groups, and populations: societal view. Health Aff (Millwood). 2007; 26:1220-30.

17. Milbrett P, Halm M. Characteristics and predictors of frequent utilization of emergency services. J Emerg Nurs. 2009; 35:191-8.
18. Moore $G$, Gerdtz M, Manias E, Hepworth G, Dent A. Socio-demographic and clinical characteristics of re-presentation to an Australian inner-city emergency department: implications for service delivery. BMC Public Health, 2007; 7:e320.

19. Di Giuseppe G, Abbate R, Albano L, Marinelli P, Angelillo IF; Collaborative Research Group. Characteristics of patients returning to emergency departments in Naples, Italy. BMC Health Serv Res. 2008; 8:e97.

20. Mandelberg JH, Kuhn RE, Kohn MA. Epidemiologic analysis of an urban, public emergency department's frequent users. Acad Emerg Med. 2000; 7:637-46.

21. Fuda KK, Immekus R. Frequent users of Massachusetts emergency departments: a statewide analysis. Ann Emerg Med. 2006; 48:9-16.

22. Hansagi $H$, Olsson $M$, Sjoberg $S$, Tomson $Y$, Goransson $S$. Frequent use of the hospital emergency department is indicative of high use of other health care services. Ann Emerg Med. 2001; 37:561-7.

23. Lynch RM, Greaves I. Regular attenders to the accident and emergency department. J Accid Emerg Med. 2000; 17:351-4

24. Helliwell PE, Hider PN, Ardagh MW. Frequent attenders at Christchurch Hospital's emergency department. N Z Med J. 2001; 114:160-1.

\section{COMMENTARY}

\section{They Always Will Be With Us}

B ieler and colleagues ${ }^{1}$ report that frequent visitors (defined as four or more visits per year) to an urban Swiss emergency department (ED) accounted for $4.4 \%$ of patients and made $12.1 \%$ of visits. This is consistent with other reports summarized in the review by LeCalle and Rabin. ${ }^{2}$ The review also found that frequent users in the United States were as likely to be insured, but more likely to have government insurance (Medicare/Medicaid), than other patients. The Swiss health insurance plan is similar to that of HB 3200: The America's Affordable Health Care Choices Act. Insurance is mandatory in Switzerland, and individuals buy it, although they may be subsidized by their employer or the government. There is a set of mandated basic benefits; supplemental insurance is available and people can buy high or low deductible plans. ${ }^{3}$ Ninety-five percent of the patients in the study by Bieler et al. were insured. ${ }^{1}$ Noteworthy is that Swiss frequent users were more likely to be socially vulnerable and have substance abuse and psychiatric problems. This is the same population that is likely to be recipients of U.S. government insurance. The evidence seems fairly consistent: insurance will not decrease ED use among frequent users. Most frequent users do so for medical and social reasons, not for economic ones. The 2009 Academic Emergency Medicine consensus conference presented a research agenda for studying ED identification of socially vulnerable patients. ${ }^{4-6}$ This research could lead to effective ways to direct these patients to care that is more suited to their needs.

\section{Lowell W. Gerson, PhD}

(Igerson@neomed.edu)

Senior Associate Editor, Academic Emergency Medicine Department of Family and Community Medicine Northeast Ohio Medical University Rootstown, $\mathrm{OH}$

Emergency Medicine Research Center Department of Emergency Medicine Summa Health System Akron, $\mathrm{OH}$

\section{Mark Hauswald, MS, MD}

Senior Associate Editor, Academic Emergency Medicine Department of Emergency Medicine University of New Mexico School of Medicine Albuquerque, NM

Supervising Editor: David C. Cone, MD. 